\title{
Aubrey Milunsky and Jeff M. Milunsky: Genetic Disorders and the Fetus-Diagnosis, Prevention, and Treatment
}

\author{
Seventh Edition: 2016, Wiley Blackwell, New Jersey, ISBN: 78-1-118-98152-8
}

\author{
Ishwar C. Verma ${ }^{1}$
}

Received: 13 July 2016/ Accepted: 19 July 2016/Published online: 26 July 2016

(C) Society of Fetal Medicine 2016

The Seventh Edition of this classic text has been edited with customary care and attention devoted by the two Milunskys. It consists of 34 chapters and represents the most extensive coverage of prenatal diagnosis of genetic disorders.

The first chapter on genetic counseling is excellent and should be compulsory reading for all medical geneticists. The second chapter is fully devoted to fetal procedures and provides extensive review of the topic. The next three chapters cover prenatal diagnosis of neural tube defects, autosomal disorders, and sex chromosome abnormalities. There is a good chapter on molecular cytogenetics as applied to prenatal diagnosis, apart from a separate one on microarray analysis.

Most of common disorders such as fragile X syndrome, skeletal dysplasias, cystic fibrosis, hemoglobinopathies, primary immune deficiency disorders, etc. are well covered. A separate chapter is devoted to biochemical screening as well as noninvasive prenatal diagnosis, preimplantation genetic diagnosis, fetal medical and surgical therapies, and fetal diagnosis by ultrasound. There is also a chapter on ethical issues as well as counseling after prenatal loss.

Overall, the book maintains the high standard of previous editions and represents the best source of information on prenatal diagnosis of genetic disorders. My doubts on clinical questions are often cleared by referring to this volume. The book should be on the shelf of all departments of medical genetics and fetal medicine specialists.

Ishwar C. Verma

jfm200@yahoo.co.in

1 Institute of Medical Genetics and Genomics, Sir Ganga Ram Hospital, Rajinder Nagar, New Delhi 110060, India 